\title{
ENUNCIADO NO ENUNCIADO, ENUNCIADO SOBRE 0 ENUNCIADO: \\ O CÍRCULO DE BAKHTIN POR C. BRANDIST
}

\section{UTTERANCE WITHIN UTTERANCE, UTTERANCE ABOUT UTTERANCE: THE BAKHTIN CIRCLE BY C. BRANDIST}

RENATA COELHo MARCHEZAN*

RESUMO: Considerando a pertinência das pesquisas que tratam das fontes e do contexto histórico e intelectual das reflexões do chamado Círculo de Bakhtin, examinam-se, aqui, os estudos de Craig Brandist, organizados nos seguintes itens: (1) identificação das diferentes fontes de M. Bakhtin, V. N. Volochínov e P. Medviédev; (2) exame dos escritos bakhtinianos de diferentes épocas, com demarcação de diferentes períodos das produções; (3) relativização do papel de Bakhtin como mentor do grupo; (4) indicação da filosofia alemã como a principal fonte dos estudiosos do grupo. Ao longo da reflexão, assim organizada, busca-se apresentar e problematizar

* Docente da Unesp - Universidade Estadual Paulista. E-mail: renata_marchezan@uol.com.br . 
as contribuições do estudioso inglês para a compreensão da obra do Círculo, especialmente, em relação às diferenças de autoria e às influências que recebe.

PALAVRAS-CHAVE: Bakhtin. Círculo de Bakhtin. Autoria.

ABSTRACT: Considering the relevance of the research dealing with historical and intellectual sources and the context of the so-called Bakhtin Circle's works, this article examines the studies of Craig Brandist organized in the following items: (1) the different sources of M. Bakhtin, V. N. Volochínov and P. Medviédev; (2) the Circle's writings from different periods, with demarcation of different stages of the production; (3) the questioning of Bakhtin's role as the mentor of the Circle; (4) the German philosophy as the main source of the group. Organized in this way, this article presents and discusses the contributions of Brandist to the understanding of the Circle's work, especially concerning the differences of authorship and the influences it receives.

KEYWORDS: Bakhtin. The Bakhtin Circle. Authorship.

O discurso citado é o discurso no discurso, a enunciação na enunciação, mas é, ao mesmo tempo, um discurso sobre o discurso, uma enunciação sobre a enunciação.

V. N. Volochínov

Como em qualquer campo do conhecimento, e, em especial, nas ciências humanas, é inegável a relevância das pesquisas que investigam o contexto histórico e teórico das reflexões 
do chamado Círculo de Bakhtin. Neste caso, revestem-se de especial importância, dada a maneira conturbada - como se sabe, em função das adversidades, principalmente políticas, que caracterizaram a época - como foram produzidas e publicadas as reflexões. A essa dificuldade se soma também a nossa "distância" do contexto soviético.

Nessa linha de investigação, destacamos, neste trabalho, as contribuições de Craig Brandist, estudioso do contexto intelectual e cultural dos primeiros anos da União Soviética. Em

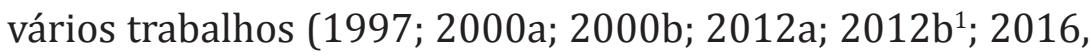
no prelo) e, especialmente, em seu livro de 2002, The Bakhtin Circle: philosophy, culture and politics, Brandist examina as fontes ${ }^{2}$ intelectuais que sustentam quase toda a obra de M. Bakhtin, V. N. Volochínov e P. Medviédev. O estudioso inglês entende que seu trabalho auxilia na desmitificação de Bakhtin como um pensador único, extremamente original. Lembra que é essa mesma a tarefa da história intelectual que não é uma "galeria de grandes pensadores individuais, mas uma história das ideias em sua formação sócio-histórica, enredada em instituições e em batalhas ideológicas"3 (BRANDIST, 2002, p. ix, tradução nossa).

Os estudos de Brandist orientam-se também para minimizar os problemas que recebemos juntamente com a herança bakhtiniana, que são elencados por ele: publicação das obras fora da ordem de produção e sem preparação de seus próprios autores; falta de acesso a manuscritos; disputa sobre a autoria de obras, motivada por ideologia e interesses

1 Neste livro, Maria Inês Campos e Rosemary H. Schettini reúnem artigos de C. Brandist, originalmente publicados entre 1999 e 2008.

2 Para ele, são mesmo "fontes", não "confluências", como preferem outros estudiosos.

3 Conforme o original: "a gallery of great individual thinkers, but a history of ideas in their socio-historical becoming, enmeshed in institutional forms and ideological battles". 
financeiros; edição pobre dos textos; traduções ruins; problemas terminológicos; idealização dos estudiosos. (BRANDIST, 2002, p. 01-12; 2012b).

Em interlocução com extensa relação de outros estudiosos do Círculo ${ }^{4}$, o exame que Brandist realiza do material pesquisado e consultado em arquivos, tanto em relação ao contexto sócio-histórico e intelectual do Círculo, como também às suas circunstâncias profissionais e pessoais, constituem uma análise incisiva, que se caracteriza por:

- considerar as diferenças entre as reflexões dos membros do Círculo;

- reconhecer diferenças entre os escritos de diferentes épocas e demarcar fases cronológicas com base nas características das produções;

- relativizar o papel de Bakhtin como mentor do grupo;

- identificar as principais fontes dos membros do grupo.

Os itens acima ressaltam diferentes aspectos do estudo de Brandist que, no entanto, estão, obviamente, muito relacionados. Isso se mostrará, a seguir, na nossa consideração e, por vezes, problematização de cada um deles.

\section{As diferenças entre o pensamento de Bakhtin, Medviédev e Volochínov}

Brandist examina as fontes do pensamento de Bakhtin, Medviédev e Volochínov, de modo a marcar diferenças en-

4 Destacamos o artigo de Tihanov (1998), sobre a sociologia marxista de Volochínov e o de Poole (1998), que examina, em Bakhtin, a influência de Cassirer, tanto em relação aos temas eleitos, quanto ao método adotado. 
tre eles. Essa é a orientação escolhida justamente porque as obras do Círculo vinham sendo tomadas, por muitos estudiosos, como um todo homogêneo, perspectiva favorecida pela consideração de Bakhtin como autor das chamadas "obras disputadas", entre elas, 0 método formal nos estudos literários: introdução crítica a uma poética sociológica (MEDVIÉDEV, 2012) e Marxismo e filosofia da linguagem: problemas fundamentais do método sociológico na ciência da linguagem (BAKHTIN/VOLOCHINOV, 1979) ${ }^{5}$. Embora não subestime a colaboração entre os três pensadores, Brandist toma clara posição em relação à disputa autoral ${ }^{6}$ : sua reflexão o leva a reforçar a indicação de Medviédev e Volochínov como respectivos autores das duas obras indicadas acima e das demais de autoria disputada com Bakhtin.

Além de buscar argumentos em dados biográficos e considerar a diferença de tom e estilo entre os autores, Brandist baseia-se também, como dissemos antes, no exame das bases filosóficas dos autores. Enfatiza, mais em Bakhtin do que em Volochínov e Medviédev, as influências das ideias neokantistas, em especial as de E. Cassirer - e, aqui, ressaltaríamos também as de G. Simmel ${ }^{7}$. Já nas obras de Medviédev e Volochínov, o envolvimento com o marxismo, expresso, inclusive, em acentuados argumentos de defesa de sua relevância, vai se mostrar na "abordagem sociológica" da língua e da literatura

5 Essa referência apenas indica a autoria tal como consta da publicação brasileira. As demais referências das obras do Círculo, neste artigo, também seguem as publicações brasileiras.

6 Às interessantes discussões sobre a autoria das obras (entre elas, VASILEV, 2006; MORSON; EMERSON, 2008; SÉRIOT, 2010), juntam-se, mais recentemente, Medviédev; Medviédeva; Shepherd, (2016).

7 G. Simmel é neokantista, e se vinculará à chamada filosofia da vida (Lebensphilosophie), sendo considerado, ainda, um precursor da sociologia (GOLDTHORPE, 1971; GIDDENS, 1971). 
que empreendem. Nas palavras de Brandist (2002, p. 54, tradução nossa), "os autores estão tentando construir uma ponte entre filosofias idealistas da cultura e o marxismo e, como uma extensão disso, uma ponte entre a liderança política e a intelligentsia mais tradicional a que pertenciam"8. A ponte a que Brandist se refere é a aproximação entre o kantismo/ neokantismo e o marxismo, que, apesar das controvérsias, era uma preocupação filosófica e social constante na época ${ }^{9}$.

Em suas proposições acerca das relações entre a infraestrutura e a superestrutura, Volochínov e Medviédev - e antes deles, com relativas diferenças, G. Plekhanov e N. Bukharin incorporam reflexões que remontam aos conceitos de cultura objetiva e cultura subjetiva, problematizados pelo neokantismo (TIHANOV, 1998; BRANDIST, 2000a; 2002), e, gostaríamos de enfatizar novamente, também por Simmel. Na relação entre as forças materiais e a ideologia, é introduzido "o meio ideológico", nos termos de Medviédev (2012, p.56), ou "o terceiro reino" (VOLOCHINOV, 2013b, p. 255), "a ideologia do cotidiano", "a psicologia social” (BAKHTIN/VOLOCHINOV, 1979), nos termos preferidos por Volochínov. Com a interposição desse lugar, os autores sustentam a tese de que não há uma determinação direta da consciência nem dos objetos culturais pelo sistema econômico. Esse lugar intermediário é o cotidiano, considerado como um fluxo incessante da vida, em que as consciências são constituídas em meio a valores, crenças e contradições, antes de serem estabilizados nos domínios da cultura. Desse modo, a ideologia não é entendida apenas como reflexo, como um segundo produto das bases, mas também "um produto que

8 Conforme o original: "the authors are trying to form a bridge between idealist philosophies of culture and Marxism and, as an extension of this, a bridge between the political leadership and the more traditional intelligentsia to which they belonged".

9 Também de acordo com Tihanov (1998, p. 600). 
produz" (TIHANOV, 1998, p. 603).

0 elemento ativo desse lugar intermediário é a linguagem, em cuja concepção Brandist detecta o dilema (2002; 2012b) de Volochínov entre dois fundamentos inconciliáveis, um de base idealista, outro, realista: de um lado, "as formas simbólicas" de E. Cassirer e, de outro, a distinção rigorosa do antikantista K. Bühler entre "o campo dêitico" e "o campo simbólico" da linguagem (2002; 2012b).

Entre as influências neokantistas, a de Cassirer, segundo Brandist, teria se tornado aparente nas obras do Círculo primeiramente em Volochínov. De qualquer modo, seus estudos acabam por nos levar de volta ao reconhecimento de bases filosóficas comuns entre Bakhtin, Medviédev e Volochínov, mas não nos esqueçamos, então, do desafio particularmente assumido por Medviédev e Volochínov em aproximarem-se do marxismo.

A posição de Brandist em relação à autoria das obras disputadas, embora pareça predominar atualmente, não é um consenso. No entanto (e fazendo uso das noções bakhtinianas de autor-pessoa e autor-criador), se podem restar dúvidas sobre a justeza em atribuir a autoria das obras a um ou outro autor-pessoa, o reconhecimento de autores-criadores distintos parece-nos prudente. Em outras palavras, o estudo, o desenvolvimento ou a aplicação do que chamamos dialogismo serão mais coerentes e produtivos se for reconhecida a diversidade de direções.

\section{Os períodos do pensamento do Círculo de Bakhtin}

Como mencionamos anteriormente, no exame das obras 
do Círculo, Brandist opta por explorar as diferenças entre os escritos de diferentes épocas e demarca períodos com base em suas características. Considera importante o reconhecimento das diferenças e argumenta que um dos motivos que o inibiram foi a ordem das leituras, inversa à cronologia da produção das obras. Os trabalhos posteriores foram lidos primeiramente e, assim, animaram a leitura dos iniciais, o que prejudicou a exploração e, em alguns casos, até a percepção das descontinuidades das reflexões.

As fases propostas por Brandist (2002, p. 12) obedecem, na medida do possível, a ordem cronológica das obras, mas, mais do que isso, expõem os resultados da análise realizada. As duas etapas iniciais compreendem as reflexões do grupo e as outras seguem acompanhando o trabalho de Bakhtin, que, como sabemos, viveria mais do que seus companheiros. Os períodos demarcados podem ser indicados sucintamente:

\section{1‥ Período}

Em 1919-26, situam-se trabalhos filosóficos iniciais sobre ética e estética, em que estão incluídos, "Arte e responsabilidade" (BAKHTIN, 2003), Para uma filosofia do ato responsável (BAKHTIN, 2010), “O autor e o herói” (BAKHTIN, 1997a) e "O problema do conteúdo, do material e da forma na criação literária” (BAKHTIN, 1988b).

Na apresentação desse período, Brandist recupera as influências filosóficas do Círculo - entre outras, o neokantismo, de H. Cohen e P. Natorp, a filosofia da vida, de G. Simmel, e a fenomenologia, de E. Husserl e M. Scheler - e destaca o papel de M. Kagan, membro do Círculo, no debate do neokantismo dentro do grupo.

Nesse período, o exame da arquitetônica do mundo 
concreto, fundada nos centros valorativos do eu e do outro, operada pelos conceitos de responsabilidade e exterioridade, articula ética e estética, ambas, como nota Brandist, desprovidas ainda de historicidade, embora, como também pondera, o neokantismo adotado pelo Círculo tenha constituído os fundamentos filosóficos da sociologia clássica.

Acompanhando a datação de Brandist, segundo a qual Bakhtin teria lido Cassirer apenas nos anos 1930, Lofts (2016) argumentará que é imperioso reconhecer, então, uma incrível convergência entre Cassirer e Bakhtin, já em Para uma filosofia do ato responsável, em que aparece a preocupação com o evento de fala, o "evento-textual" - para ele, germe do que se tornaria o dialogismo bakhtiniano. Lofts lembra que, nessa obra, se revela um Bakhtin situado no domínio neokantista, mas, do mesmo modo que Cassirer, crítico em relação às suas análises abstratas, que anulam o indivíduo, o ato concreto. Um Bakhtin que se mostra inclinado, sem aderir totalmente, a propostas como as da filosofia da vida, que relaciona o "mundo da vida" e o "mundo da cultura". Para Lofts, não se trataria, portanto, de influências, mas de convergências. Buscavam ambos, Bakhtin e Cassirer, "conciliar duas posições filosóficas antitéticas dominantes no início do século $\mathrm{XX}^{10}$ : a filosofia transcendental de Kant e o Neokantismo, de um lado, e a Lebensphilosophie [filosofia da vida] de Simmel, Bergson e Heidegger, de outro" (LOFTS, 2016, p. 82). Resume Lofts, usando as palavras de Cassirer: "no princípio era o ato" (2000, p.51 apud LOFTS, 2016, p.82).

100 contexto histórico do pós-guerra exigia respostas que uma filosofia formal e abstrata não podia fornecer (Brandist, 2002). É nesse contexto que os neokantistas Cassirer e Simmel deslocam-se em direção à filosofia da vida, e este último, também em direção a estudos precursores da sociologia. Como vemos, aqui, não estavam sozinhos. 
2ํ․ Período

Em 1927-29, Brandist assinala o trabalho de Bakhtin, de 1929, sobre Dostoiévski, que seria publicado com reformulações apenas em 1963, e os trabalhos de autoria disputada, em que destaca a reflexão sobre a linguagem e a significação. Além das duas obras disputadas mencionadas anteriormente, inclui duas outras de Volochínov: "Palavra na vida e a palavra na poesia: introdução ao problema da poética sociológica" (2013a) e Freudismo (BAKHTIN, 2001) ${ }^{11}$.

Essas obras marcam, para Brandist, a "virada linguística" ("ou virada semiótica") do Círculo, em que os conceitos de enunciado e interação verbal - que Volochínov opera na esteira, principalmente, das proposições de K. Bühler, e também de A. Marty (não nos esquecendo, no entanto, da anteriormente mencionada influência de Cassirer) - possuem especial importância. Para Brandist, estaria, dessa maneira, aberto o caminho para a noção de diálogo que seria explorada por Bakhtin, diferentemente, do que propõe Lofts, como vimos.

O trabalho sobre Dostoiévski, de 1929, significa, para Brandist, a transposição das preocupações presentes em "O autor e o herói” para o domínio da linguagem, para a abordagem do discurso no romance. É também a obra que traz, pela primeira vez, embora sem desenvolvê-la, uma explicação sócio-histórica da forma literária (2002, p. 93).

Embora as obras disputadas sejam cronologicamente próximas do trabalho de Bakhtin sobre Dostoiévski, Brandist vai destacar a precedência do envolvimento de Volochínov e de Medviédev com o tema da linguagem (lembremos, todavia, das ponderações de Lofts, antes apresentadas), com base

11 Ver nota 5. 
em argumentos que incluem a atuação dos dois estudiosos no Instituto de Pesquisa em História Comparada de Literaturas e Línguas Ocidentais e Orientais (designado em russo pela sigla ILJaZV) ${ }^{12}$.

Nesse contexto intelectual, Brandist (2002; 2012b) aponta o aparecimento de preocupações sociolinguísticas pioneiras, também em relação ao ocidente. Segundo o estudioso, os anos 1920 foram especialmente frutíferos para a consideração da diversidade linguística e cultural da Rússia e da própria URSS, constituindo um intervalo entre dois momentos de afirmação de uma língua imperial única. Após esse período soviético de valorização da diversidade, fomentada por política do próprio Estado, volta-se, também pelo comando do Estado, à afirmação do russo como língua oficial.

A consideração da linguagem, do signo e da literatura em perspectiva sociológica/marxista ${ }^{13}$ leva Brandist a localizar, também nesse período, uma "virada histórica"14.

\section{3ํ․ Período}

Em 1934-41, Brandist demarca os trabalhos de Bakhtin sobre o romance, sua constituição histórica e sua definição como gênero. Inclui, aqui, textos que estão na publicação brasileira Questões de literatura e de estética: a teoria do romance (BAKHTIN, 1988a): "O discurso no romance”, "Formas de tem-

12 Em artigo recente, Brandist (2016) detalha que Voloshínov e de Medviédev trabalharam no ILJaZV, em que atuou o linguista Nikolai Marr entre 1925 e 1932, e em que não se tem registro da presença de Bakhtin nos seminários, embora seja provável que acompanhasse o que ali se produzia.

13 A aproximação entre sociologia e marxismo também era muito praticada, a despeito de restrições e polêmicas vigentes na época.

140 termo está mesmo no título de seu artigo "A virada histórica de Bakhtin e seus antecedentes soviéticos" (BRANDIST, 2016). 
po e de cronotopo no romance (Ensaios de poética histórica)", "Da pré-história do discurso romanesco", "Epos e romance".

Brandist localiza também nesses textos a inflexão de Bakhtin em direção às mudanças fomentadas por Volochínov e de Medviédev e dedica-se a examinar o modo como Bakhtin incorpora, então, preocupações com a história, com a linguagem e com os gêneros discursivos, na esteira de Cassirer, que, por sua vez, integra a dialética hegeliana. Heteroglossia é um dos conceitos que investiga em meio ao debate filosófico da época, em especial acerca do hiato (mais uma vez) entre vida e cultura.

\section{4․ Período}

Em 1940-63, estão os escritos de Bakhtin sobre literatura e cultura popular: Problemas da poética de Dostoiévski (BAKHTIN, 1981), A cultura popular na Idade Média e no Renascimento: o contexto de François Rabelais (BAKHTIN, 1999) e "Rabelais e Gógol (Arte do discurso e cultura cômica popular)" (BAKHTIN, 1988c). Para Brandist, Bakhtin ocupa-se de Rabelais e Goethe ${ }^{15}$ por serem representantes nem tanto de inovações literárias, mas, sim, de suas respectivas épocas. Bakhtin teria depreendido deles "o romancista como filósofo", motivado pelas reflexões de Cassirer sobre o renascimento e o iluminismo (BRANDIST, 1997, 2002) ${ }^{16}$. Brandist também recupera as ideias soviéticas e alemãs que embasaram a perspectiva histórica por meio da qual Bakhtin expõe

15 No capítulo em que examina esse período, Brandist menciona também o estudo "O romance de educação na história do realismo" (BAKHTIN, 1997b), cuja data de produção, no entanto, figura entre 1936-1938.

16 Em sua argumentação a esse respeito, Brandist refere-se aos trabalhos de Poole, entre eles o já citado artigo de 1998. 
o desenvolvimento do romance e do carnaval. Mais uma vez, a relação entre vida e cultura está presente tanto na reflexão sobre o romance - gênero que acolhe a diversidade de vozes, de línguas, de outros gêneros - quanto no conceito de carnaval, que compreende uma inversão nas forças estabilizadoras da cultura.

A perspectiva histórica de Bakhtin segue a abordagem de Cassirer, e também a dos trabalhos sobre a origem das línguas de N. Marr, mesmo porque este também fora influenciado por aquele. Na comparação que faz entre as duas versões da obra de Bakhtin sobre Dostoiévski, Brandist assinala o acréscimo do capítulo sobre gênero e as inclusões e alterações que resultam em uma perspectiva histórica mais fundamentada do escritor russo, que, no entanto, ressalva Brandist, carece de bases materiais. Os trechos a seguir mostram os termos da crítica formulada:

Bakhtin não fundamenta sua discussão sobre a cultura festiva popular em pesquisa histórica sustentada. Em vez disso, o carnaval é, para Bakhtin, uma espécie de "protogênero" descrito em termos antropológicos. Esse "gênero" reaparece de diferentes maneiras ao longo da história da literatura; formas genéricas específicas e identificáveis são, na verdade, consideradas como tendo existido em várias manifestações em todos os momentos da História. (...) Um gênero sempre é, portanto, tanto antigo quanto novo, já que as mesmas características aparecem, de outras maneiras, renovadas e "contemporizadas" (BRANDIST, 2002, p. 137-8, tradução nossa) ${ }^{17}$.

17 Do original: "Bakhtin does not base his discussion of popular festive culture on sustained historical research. Instead, carnival is for Bakhtin a sort of 'proto-genre' described in terms of anthropology. This 'genre' reappears in different guises throughout the history of literature; indeed, specific and identifiable generic forms are considered to have existed in various manifestations at all points of history. (...) A genre is therefore always both old and new, for the same features appear in new ways, renewed and 'contemporised'". 
5․ Período

Em 1963-75, Brandist assinala os ensaios que considera metodológicos: "Os gêneros do discurso" (BAKHTIN, 1997c), "Observações sobre a epistemologia das Ciências Humanas" (BAKHTIN, 1997g), "Apontamentos de 1970-1971" (BAKHTIN, 1997f), "O problema do texto" (BAKHTIN, 1997d), "Os estudos literários hoje” (BAKHTIN, 1997e).

0 estudioso inglês não deixa de reconhecer a relação desses trabalhos com outros - a perspectiva neokantista; a noção de enunciado, definidora da "metalinguística" -, mas destaca seu propósito metodológico: a definição do objeto das ciências humanas; o estabelecimento do texto como dado primário; a afirmação da monologia das ciências exatas em contraste com a dialogia das ciências humanas, sustentada ainda de acordo com W. Dilthey, apesar de já relativizar essa diferença; a proposição do conceito de gênero como base para as ciências humanas; a importância da relação entre gêneros primários e secundários, cuja distinção remete aos domínios da vida e da cultura.

\section{Relativização do papel de Bakhtin como mentor do grupo}

No tipo de pesquisa que é a de Brandist, não poderia ser diferente: há a preocupação com uma intrincada datação de trabalhos, de dados biográficos e de fatos. Nessa direção, o estudo relativiza o papel de Bakhtin como mentor do Círculo, com o entendimento de que Medviédev e Volochínov é que teriam trazido ao grupo o interesse pela linguagem e sua dimensão sócio-histórica, que não é central nos primeiros tra- 
balhos de Bakhtin, do modo como se tornará depois. Brandist questiona, inclusive, a importância do próprio grupo, uma vez que seus membros participaram de outros círculos e institutos de pesquisa.

O posicionamento de Brandist não é consensual: para Bubnova, constitui "juízo de valor", e não "simples esclarecimento de fatos" (2011). De nossa parte, lembramos o movimento inverso, também assinalado por Brandist: em especial, o aproveitamento que Volochínov faz da reflexão de Bakhtin sobre o eu e o outro em sua problematização da enunciação (2002, p. 65). Visto assim, de outro ângulo, o pensamento de Bakhtin teria alimentado as reflexões de Volochínov. E Brandist não deixa mesmo de reconhecer a instigante e fecunda contribuição de Bakhtin.

O exame das obras do Círculo mostra desenvolvimentos que os períodos demarcados por Brandist iluminam bem. No entanto, o mesmo neokantismo presente em Bakhtin está também, como vimos, entrelaçado ao marxismo de Volochínov e Medviédev. Esse neokantismo, que é também aquele problematizado por Cassirer e Simmel, permite reconhecer uma linha de continuidade nas reflexões, mais do que grandes rupturas. Em toda ela, contra o teoricismo, impõe-se a relação entre a vida e as formas culturais.

\section{Principais fontes do Círculo}

Os trabalhos de Brandist compõem uma ampla e complexa rede que desenha o contexto intelectual e histórico das obras do Círculo de Bakhtin. A filosofia alemã sobressai às demais fontes, não sem as marcas, no entanto, que lhe são imprimidas, principalmente, pelo marxismo e pelas circunstân- 
cias soviéticas, das quais surgem, por exemplo, a preocupação com a diversidade linguística e o marrismo.

Em meio a todos os aportes filosóficos, o exame das pesquisas de Brandist permite perceber sua ênfase na influência neokantista, especialmente, em Bakhtin, revelada (i) na adoção da separação rígida entre as ciências naturais e culturais, aquelas baseadas em determinações e estas, na jurisprudência $^{18}$; (ii) no conceito de sujeito, considerado como portador de direitos e responsabilidades; (iii) no entendimento de que o conhecimento do mundo empírico é impossível (BRANDIST, $2002 ; 2012 b)$.

Embora reafirme o envolvimento de Bakhtin com o neokantismo, Bubnova (2011), no artigo anteriormente citado, considera que não há, por Bakhtin, uma aceitação irrestrita das teses kantistas e neokantistas, e problematiza cada um dos postulados apontados por Brandist. Lembra que Bakhtin, em seus últimos textos, refuta a existência de uma "fronteira intransponível" (1997f, p.385) entre as ciências humanas e as ciências naturais: "a coisa e a pessoa são apenas extremos, e não substâncias absolutas" (1997g, p.408) ${ }^{19}$. Em relação ao sujeito em Bakhtin, a autora pondera que está longe do sujeito neokantista, possuidor de direitos e responsabilidades abstratas. Dentre as inúmeras vezes em que Bakhtin afirma a importância do "concreto", Bubnova recorre à concepção do ato ético "como um acontecer enraizado na relação concreta com o outro, vivencial, única e singular" (2011, p.28).

0 próprio Brandist não deixa também de apontar, em Bakhtin, a enfática rejeição ao tratamento da consciência

18 Brandist dedica um artigo a essa questão (2012a).

19 Substituímos o trecho citado por Bubnova, traduzido diretamente do russo, pelo que consta da publicação brasileira. 
como um universal abstrato; na verdade, a enfática rejeição à abstração. Brandist constata a substituição da "consciência em geral" por uma consciência intencional (2002, p. 39), fenomenológica, que percebe o mundo em atos. 0 que Brandist quer enfatizar, no entanto, é a importância do jurídico que remonta à relação entre cognição e juízo, e nos remete também ao terceiro postulado - aliás, os três postulados apontados encaminham, conjuntamente, a objeção de Brandist à obra de Bakhtin -, elencado acima: "o objeto da cognição [tal como o juízo no direito] é (...) produzido pelo e no pensamento, no próprio processo da cognição, com o objeto transcendente (o mundo empírico) tornando-se incognoscível" (BRANDIST, 2012b, p. 69).

Elegendo a concretude e, ao mesmo tempo, assumindo a incognoscibilidade do mundo empírico, a obra de Bakhtin, para o estudioso inglês, mostra-se "ambivalente" ou, ainda, "retórica" no acolhimento da materialidade. Para Brandist, a impossibilidade do conhecimento empírico, sustentada por Bakhtin, significa a desconsideração de fatores biológicos e econômicos, em favor do tratamento de imagens, tais como as imagens do corpo, no estudo sobre Rabelais. Brandist não se esquece das reflexões sobre a linguagem que discutem a estratificação social, mas as considera desprovidas de qualquer discussão sobre suas bases materiais e institucionais. Assim como a consideração da política, que, para ele, é formalizada e absorvida na ética (2002).

Brandist procura em Bakhtin uma teoria social que não encontra. Segundo ele, para ser usada pela teoria social, a obra de Bakhtin precisaria de complementação, principalmente por não considerar as bases materiais da sociedade (2002, 2012a).

A impossibilidade do conhecimento do mundo empíri- 
co, do meramente dado, fora da consciência, constitui o argumento principal de Brandist em sua consideração do "idealismo"20 neokantista em Bakhtin. Na resposta de Bubnova a Brandist, que vínhamos seguindo, a autora recoloca a questão: Bakhtin não assume uma ruptura total entre o homem e o mundo, mas, sim, interpõe a linguagem entre eles. Bubnova refere-se ao "giro linguístico" 21 , que coloca a linguagem como um tema central na filosofia do século $X^{22}$ (2011, p.29).

Não se trata, aqui, no entanto, de reconhecer na relação homem/mundo o papel do sistema linguístico, das estruturas semióticas, nem de um discurso interior, preso à consciência individual. Diferentemente de outros pensadores do século XX, em Bakhtin - bem como em Volochínov e Medviédev -, a importância da linguagem está configurada no enunciado, que circula no cotidiano, na cultura. É nele e por meio dele que acontecem o encontro, o embate de vozes, o processo de compreensão do mundo e o próprio processo de constituição da consciência. Processos que explicam o caráter social, cultural do sujeito bakhtiniano ${ }^{23}$.

Bakhtin valoriza, em especial, a vida cotidiana, cronotopo em que circulam os diálogos mais vivos, menos sistematizados, e também em que o eu e o outro, sem álibi, são confrontados com seus atos, com a responsabilidade sobre eles.

Aquilo que, para Simmel, é a "tragédia da cultura” (2000), a inevitável separação entre o mundo da vida e o mundo da cultura, em função da sistematização e autonomização das

20 Questão retomada em Brandist (no prelo), artigo de coletânea organizada por Luciane de Paula.

21 Ou "virada linguística", conforme se adotou acima.

22 De sua parte, Brandist (2000b, 2002) também está atento a esse tema.

23 Tratamos disso em Marchezan (2015). 
esferas culturais, que acabam por se tornar alheias à vida, ao homem, preocupa Bakhtin desde seu primeiro pequeno texto (BAKHTIN, 2003). Em resposta a ela, valoriza o mundo da vida, mas não o opõe à teoria - ao modo do que vê em Bergson (BAKHTIN, 2010, p.59-60): o indivíduo depende da validade teórica, mesmo que esta não dependa daquele. Para Bakhtin, é o ato concreto e irrepetível da vida o centro de articulação entre vida e cultura. Por isso mesmo, não poderia ser favorável à dicotomia dos formalistas entre linguagem poética e linguagem prática. Por isso também, explora a relação entre os gêneros primários e os gêneros secundários, "os tipos relativamente estáveis de enunciados", que circulam, respectivamente, no cotidiano e nas esferas sistematizadas da cultura.

\section{Enunciado no enunciado, enunciado sobre o enunciado}

Centrais nas reflexões do Círculo, a citação, a referência ao enunciado do outro, o enunciado no enunciado são também o enunciado sobre o enunciado, a resposta do discurso ao discurso. Focalizamos, neste artigo, a palavra de Brandist sobre a palavra de Bakhtin, Volochínov e Medviédev, uma resposta competente, que, ao expor a obra do Círculo, também expõe sua própria posição valorativa, em outros termos, sua própria posição ideológica.

Brandist defende a necessidade de um conhecimento histórico das obras do Círculo, para que, estudadas com a profundidade que merecem, possam ser-lhes reconhecidas as potencialidades e também as limitações. Por serem mesmo estimulantes, as ideias do Círculo, precisam ser tratadas criticamente. Levadas à mente e não ao coração, conforme salienta. 
A contribuição de Brandist, que se mostra em um coerente tratamento de dados, busca examinar tanto as diferenças, as descontinuidades na obra do Círculo de Bakhtin, internamente considerada, quanto as semelhanças, as continuidades entre a obra e suas fontes. Com as primeiras, Brandist problematiza as considerações da obra como um conjunto (totalmente) coerente; com as últimas, problematiza as afirmações de sua (extrema) originalidade.

\section{REFERÊNCIAS}

BAKHTIN, M. Para uma filosofia do ato responsável. Trad. aos cuidados de Valdemir Miotello e Carlos Alberto Faraco. São Carlos: Pedro \& João Editores, 2010.

BAKHTIN, M. Arte e responsabilidade. IN: BAKTIN, M. Estética da criação verbal. Introdução e tradução do russo Paulo Bezerra; prefácio à edição francesa Tzvetan Todorov. São Paulo: Martins Fontes, 2003. p. XXXIII-XXXIV.

BAKHTIN. M. 0 freudismo: um esboço crítico. Tradução de Paulo Bezerra. São Paulo: Perspectiva, 2001.

BAKHTIN. M. A cultura popular na Idade Média e no Renascimento: o contexto de François Rabelais. Tradução de Yara Frateschi Vieira. São Paulo: Hucitec; Brasília: Editora da Universidade de Brasília, 1999.

BAKHTIN, M. O autor e o herói. IN: BAKHTIN, M. Estética da criação verbal. Tradução a partir do francês por Maria Ermantina Galvão G. Pereira; revisão da tradução Marina 
Appenzeller. 2. ed. São Paulo: Martins Fontes, 1997a. p. 23220.

BAKHTIN, M. O romance de educação na história do realismo. IN: BAKHTIN, M. Estética da criação verbal. Tradução a partir do francês por Maria Ermantina Galvão G. Pereira; revisão da tradução Marina Appenzeller. 2. ed. São Paulo: Martins Fontes, 1997b. p. 221-234.

BAKHTIN, M. Os gêneros do discurso. IN: BAKHTIN, M. Estética da criação verbal. Tradução feita a partir do francês por Maria Ermantina Galvão G. Pereira; revisão da tradução Marina Appenzeller. 2. ed. São Paulo: Martins Fontes, 1997c. p. 277-326.

BAKHTIN, M. O problema do texto. IN: BAKHTIN, M. Estética da criação verbal. Tradução a partir do francês por Maria Ermantina Galvão G. Pereira; revisão da tradução Marina Appenzeller. 2. ed. São Paulo: Martins Fontes, 1997d. p. 327358.

BAKHTIN, M. Os estudos literários hoje. IN: BAKHTIN, M. Estética da criação verbal. Tradução a partir do francês por Maria Ermantina Galvão G. Pereira; revisão da tradução Marina Appenzeller. 2. ed. São Paulo: Martins Fontes, 1997e. p. 359-368.

BAKHTIN, M. Apontamentos de 1970-1971. IN: BAKHTIN, M. Estética da criação verbal. Tradução a partir do francês por Maria Ermantina Galvão G. Pereira; revisão da tradução Marina Appenzeller. 2. ed. São Paulo: Martins Fontes, 1997f. p. 369-398. 
BAKHTIN, M. Observações sobre a epistemologia das Ciências Humanas. IN: BAKHTIN, M. Estética da criação verbal. Tradução a partir do francês por Maria Ermantina Galvão G. Pereira; revisão da tradução Marina Appenzeller. 2. ed. São Paulo: Martins Fontes, 1997g. p. 399-414.

BAKHTIN. M. Questões de literatura e de estética: a teoria do romance. Trad. Aurora Fornoni Bernardini et al. São Paulo: Unesp, Hucitec. 1988a.

BAKHTIN. M. O problema do conteúdo, do material e da forma na criação literária. IN: BAKHTIN. M. Questões de literatura e de estética: a teoria do romance. Trad. Aurora Fornoni Bernardini et al. São Paulo: Unesp, Hucitec. 1988b. p. 13-210.

BAKHTIN. M. Rabelais e Gógol (Arte do discurso e cultura cômica popular). IN: BAKHTIN. M. Questões de literatura e de estética: a teoria do romance. Trad. Aurora Fornoni Bernardini et al. São Paulo: Unesp, Hucitec. 1988c. p. 429-430.

BAKHTIN, M. Problemas da poética de Dostoiévski. 4. ed. Trad. Paulo Bezerra. Rio de Janeiro: Forense Universitária, 1981. [1929-1963]

BAKHTIN, M./VOLOCHINOV, V.N. Marxismo e filosofia da linguagem: problemas fundamentais do método sociológico na ciência da linguagem. Tradução de Michel Lahud e Yara Frateschi Vieira. São Paulo: Hucitec, 1979.

BRANDIST , C. 0 idealismo de Bakhtin e o que esse significa para as aplicações de suas ideias. Trad. Renata Coelho Marchezan. (no prelo). 
BRANDIST , C. A virada histórica de Bakhtin e seus antecedentes soviéticos. Bakhtiniana, São Paulo, vol. 11, n. 1, p. 18-41, Jan./Abril, 2016.

BRANDIST , C. O herói no tribunal da eternidade: a teoria jurídica do romance do Círculo de Bakhtin. Bakhtiniana, São Paulo, v. 7, n.1, p. 280-308, Jan./Jun., 2012a. [Trad. Renata Coelho Marchezan]

BRANDIST, C. Repensando o Círculo de Bakhtin: novas perspectivas na história intelectual. Trad. Helenice Gouvea e Rosemary H. Schettini. Organização e notas Maria Inês Campos e Rosemary H. Schettini. São Paulo: Contexto, 2012b.

BRANDIST, C. The Bakhtin Circle: philosophy, culture and politics. London: Pluto Press, 2002.

BRANDIST, C. Bakhtin, Marxism and Russian Populism. In: BRANDIST, C.; TIHANOV, G. Materializing Bakhtin. The Bakhtin Circle and social theory. London: MacMillan Press, 2000a, p. 70-93.

BRANDIST , C. Neo-Kantianism in Cultural Theory: Bakhtin, Derrida and Foucault, Radical Philosophy, v. 102, p. 6-16, 2000b.

BRANDIST, C. Bakhtin, Cassirer and Symbolic Forms. Radical Philosophy, v. 85, p. 20-27, 1997.

BUBNOVA, T. Sobre as ruínas de Bakhtin ou os perigos da isegoria. IN: PAULA, L; STAFUZZA, G. (Org.). Círculo de Bakhtin: diálogos in possíveis. Campinas, SP: Mercado de Letras, 2011. p. 19-32. 
GIDDENS, A. Georg Simmel. IN: RAISON, T. (Org.). Os precursores das ciências sociais. Trad. Luiz Corção. Rio de Janeiro: Zahar Editores, 1971. p. 149-157.

GOLDTHORPE, J. H. Introdução. IN: RAISON, T. (Org.). Os precursores das ciências sociais. Trad. Luiz Corção. Rio de Janeiro: Zahar Editores, 1971. p. 9-17.

LOFTS, S. G. Bakhtin e Cassirer: o evento e a máquina. Bakhtiniana, São Paulo, v. 11, n. 1, p. 77-98, Jan./Abril, 2016.

MARCHEZAN, R. C. A noção de autor na obra de M. Bakhtin e a partir dela. Bakhtiniana: Revista de Estudos do Discurso, São Paulo, v. 10, n. 3, p. 186-204, Set./Dez, 2015.

MEDVIÉDEV, I. P.; MEDVIÉDEVA, D. A.; SHEPHERD, D. A polifonia do Círculo. Bakhtiniana, São Paulo, v. 11, n. 1, p. 99144, Jan./Abril, 2016.

MEDVIÉDEV, P. 0 método formal nos estudos literários: introdução crítica a uma poética sociológica. Tradutoras Sheila Camargo Grillo e Ekaterina Vólkava Américo. São Paulo: Contexto, 2012.

MORSON, G. S.; EMERSON, C. Mikhail Bakhtin: criação de uma prosaística. Tradução de Antonio de Pádua Danesi. São Paulo: Edusp, 2008.

POOLE, B. Bakhtin and Cassirer: the philosophical origins of Bakhtin's carnaval messianism. The South Atlantic Quarterly, v. 97, n. 3/4, p. 537-78, Summer/Fall., 1998. 
SÉRIOT, P. Préface. In: VOLOŠINOV, V. N. Marxisme et philosophie du langage. Les problèmes fondamentaux de la méthode sociologique dans la science du langage. Nouvelle édition bilingue traduite du russe par Patrick Sériot et Inna Tylkowski-Ageeva. Limoges: Lambert Lucas, 2010. p. 13-109.

SIMMEL, G. Simmel on Culture: selected writings. Edited by David Patrick Frisby and Mike Featherstone. London: Sage Publications, 2000.

TIHANOV, G. Vološinov, ideology, and language: the birth of Marxist sociology from the spirit of Lebensphilosophie. The South Atlantic Quarterly, v. 97, n. 3/4, p. 599-621, Summer/ Fall., 1998.

VASILEV, N. L. A história da questão sobre a autoria dos "textos disputados" em estudos russos sobre Bakhtin (M. M. Bakhtin e seus co-autores). Tradução de Irina Starostina. In: FARACO, C. A.; TEZZA, C.; CASTRO, G. (Orgs.). Vinte ensaios sobre Mikhail Bakhtin. Petrópolis, RJ: Vozes, 2006. p. 290-304.

VOLOCHÍNOV, V. N. Palavra na vida e a palavra na poesia: introdução ao problema da poética sociológica. [1926]. IN: VOLOCHÍNOV, V. N. A construção da enunciação e outros ensaios. Org., trad. e notas João Wanderley Geraldi; ed. e supervisão da trad. Valdemir Miotello. São Carlos: Pedro \& João Editores, 2013a. p. 71-100.

VOLOCHÍNOV, V. N. Algumas ideias-guia para a obra Marxismo e filosofia da linguagem. IN: VOLOCHÍNOV, V. N. A construção da enunciação e outros ensaios. Org., trad. 
e notas João Wanderley Geraldi; ed. e supervisão da trad. Valdemir Miotello. São Carlos: Pedro \& João Editores, 2013b. p. 251-267.

Artigo recebido em maio de 2016 e aprovado em julho de 2016.

\section{Como citar este trabalho:}

MARCHEZAN, Renata Coelho. Enunciado no enunciado, enunciado sobre o enunciado: o Círculo de Bakhtin por C. Brandist. CASA: Cadernos de Semiótica Aplicada, São Paulo, v. 14, n. 01, p. 57-82, julho, 2016. Disponível em: <http:// seer.fclar.unesp.br/casa>. Acesso em “dia/mês/ano". http:// dx.doi.org/10.21709/casa.v14i1.8665. 